\title{
EFFECT OF WATER LEACHING ON PHOTODEGRADED POPLAR WOOD MONITORED BY IR SPECTROSCOPY
}

\author{
Zoltan Pasztory, Laszlo Tolvaj, Denes Varga \\ University OF SOPRON \\ Hungary \\ (Received February 2020)
}

\begin{abstract}
Poplar (Populus x euramericana cv. pannonia) samples were irradiated using ultraviolet light emitter mercury lamp. Other series of specimens were treated with the combination of UV radiation and water leaching. The total duration of UV radiation for both series of specimens was 20 days. The total duration of water leaching was 10 days. One cycle of the combined treatment consisted of 2-day UV radiation followed by one day water leaching. The IR measurement was carried out after both UV radiation and water leaching to monitor both effects separately. Lignin degradation of water leached samples was found to be greater than that of the solely UV treated samples. The guaiacyl and the syringyl lignin showed similar degradation properties. The unconjugated carbonyl groups generated by the photodegradation proved to be the most sensitive chemical components to leaching. As a consequence of photodegradation, two absorption bands of unconjugated carbonyl groups were grown up at 1715 and $1759 \mathrm{~cm}^{-1}$ wavenumbers. The band at $1759 \mathrm{~cm}^{-1}$ was much more sensitive to water leaching than the band at $1715 \mathrm{~cm}^{-1}$. Ten days of water leaching was long enough to remove all unconjugated carbonyls generated by the photodegradation. The water was able to leach out carbonyl groups (absorbing at $1745 \mathrm{~cm}^{-1}$ ) originally presented in poplar wood as well.
\end{abstract}

KEYWORDS: Poplar wood, photodegradation, infrared spectrum, leaching by water.

\section{INTRODUCTION}

Wood is a natural material that combines light weight with excellent physical and mechanical characteristics. Its colour ranges from red to yellow and grants a feeling of warmness. This unique coloured surface is, however, sensitive to light and heat. The most sensitive molecules of natural wood are the lignin macromolecules and most types of extractives. Extractives determine the natural colour of wood but they are sensitive to heat treatment (Chang et al. 2010, Fan et al. 2010). Wood colour is a highly sensitive indicator for monitoring the changes caused by different treatments. Objective colour measurement was successfully used to monitor the effect 
of light irradiation (Tolvaj and Faix 1995, Sharratt et al. 2009, Oltean et al. 2010, Miklecic et al. 2011, Liu et al. 2019a) temperature change (Persze and Tolvaj 2012, Tolvaj et al. 2015) and rain leaching (Kannar et al. 2018).

In the case of outdoor applications, ultraviolet (UV) portion of solar radiation and leaching by the rain are the two main factors that affect wood surface. Photodegradation of wood is a widely investigated phenomenon (Pandey 2005, Tolvaj and Mitsui 2005, 2010, Varga et al. 2017, Preklet et al. 2018). During outdoor exposure, sunlight proved to be the main factor inducing the most significant changes. Chemical analyses show that the deterioration is related primarily to the decomposition of lignin. The chromophoric groups of lignin are strong UV light absorbers. The energy of UV photons absorbed is large enough to create free phenoxyl radicals. These free radicals react with oxygen to generate carbonyl chromophoric groups (Pandey 2005, Teaca et al. 2013, Timar et al. 2016). The degradation products of lignin are responsible for the yellowing of the surface (Calienno et al. 2015, Cogulet et al. 2016).

Air humidity influences the photodegradation level of wood. Spruce and beech samples were irradiated with UV light under humid (100\% air humidity) and dry conditions to clarify the effect of vapour on photodegradation (Tolvaj et al. 2016). Treatments under wet condition resulted in considerably greater discoloration than those under dry condition. The results showed that the presence of water as vapour increased the degradation of lignin. The nonconjugated carbonyl groups absorbing around $1760 \mathrm{~cm}^{-1}$ were found not to be stable, and the number of these chemical groups decreased in the presence of vapour when compared against the dry condition.

The leaching effect of rain is the second most harmful effect during outdoor weathering of wood. However, the effect of water leaching is a hardly investigated phenomenon. Some papers deal with simultaneous light exposure and water leaching during artificial weathering (Kamdem and Greiler 2002, Hansmann et al. 2006, Fufa et al. 2013) Although, in these studies the combined effect of the two factors was investigated, their individual impact was not separated.

A recentstudy demonstrated the discoloration effect of water leaching during photodegradation of wood (Kannar et al. 2018). The leaching partly removed the yellow and red chromophore molecules generated by UV radiation. The samples become slightly lighter after water leaching. The roughness of the samples increased during UV irradiation, and the tendency of roughness change mirrored that of yellowness change.

A preliminary research was published in a book (Csanady et al. 2015) presenting the leaching effect of water during the photodegradation of beech wood. Results showed that the unconjugated carbonyl groups were partly leached out by water. A recently published paper studied the simultaneous effects of UV irradiation and water leaching on spruce wood (Bejo et al. 2019). Chemical changes were monitored by IR spectroscopy. "As a consequence of photodegradation, two absorption bands of unconjugated carbonyl groups emerged at 1714 and $1750 \mathrm{~cm}^{-1}$ wavenumbers. The band at $1750 \mathrm{~cm}^{-1}$ was much more sensitive to leaching by water than the band at $1714 \mathrm{~cm}^{-1}$. This band almost disappeared after eight cycles."

The aim of this study was the systematic investigation of the separate individual alteration effect of UV light exposure and water leaching during artificial weathering of poplar wood. The systematic treatment consisted of UV radiation and water leaching in a 2:1 time exposure ratio.

\section{MATERIALS AND METHODS}

Pannonia poplar (Populus $x$ euramericana cv. pannonia) specimens were used for the test because of its low extractive content. The dimensions of specimens were $30 \times 10 \times 5$ mm (long. $x$ rad. $x$ tang.). Both investigated series were represented by 3 samples. IR measurement was done 
on 2 fixed locations of the radial surface of each sample. Sun radiation and leaching effect of the rain, as main harmful factors effecting the degradation of outdoor wood, were simulated by the following experiments. Samples were irradiated by a mercury lamp, then plunged into distilled water at $22^{\circ} \mathrm{C}$ (wet treatment). A double mercury vapour lamp with a total electric power of $800 \mathrm{~W}$, as a strong UV light emitter, generated the light irradiation. The UV radiation was $80 \%$ of the total emission of the lamps. Specimens were located at a distance of $64 \mathrm{~cm}$ from the lamp. The temperature in the chamber was $50^{\circ} \mathrm{C}$ during the irradiation. In the first cycle, $\mathrm{UV}$ radiation time was 24 hours, followed by water leaching for 24 hours, while in the second cycle UV radiation time was doubled, 48 -hour UV radiation was followed by 24 -hour water leaching. The shorter UV radiation time was chosen at the beginning of the treatment because the degradation effect of UV radiation is very intensive at the beginning of the treatment. The second cycle was repeated up to 20 days UV treatment and 10 days water leaching. The other series of specimens were subjected to UV radiation only, without water leaching (dry treatment). The initial weight of the samples was measured at the beginning of the treatments. Wet samples were dried at room temperature up to the initial weight to generate equal moisture content for all IR measurements.

Diffuse reflectance infrared Fourier transform (DRIFT) spectrum of the samples was measured before and after treatments. Measurements were carried out with an IR spectrophotometer (JASCO FT/IR 6300). The resolution was $4 \mathrm{~cm}^{-1}$ and 64 scans were measured and averaged. The background spectrum was obtained against an aluminium plate. Two-point baseline correction at $3800 \mathrm{~cm}^{-1}$ and at $1900 \mathrm{~cm}^{-1}$ was carried out. The spectral intensities were calculated in Kubelka-Munk (K-M) units. The spectra were normalised to the band maximum around $1375 \mathrm{~cm}^{-1}$. The intensity of spectra was adjusted to 1.0 by this normalisation at maximum around $1375 \mathrm{~cm}^{-1}$. This $\mathrm{C}-\mathrm{H}$ band of cellulose is often used as internal standard because of its high intensity, central position and strong stability. The difference spectrum was calculated by subtracting the initial IR data from the data of treated sample. In this case, the absorption increase is represented by positive band while negative band represents the absorption decrease. Details and the band assignment are described in a previous work (Csanady et al. 2015).

\section{RESULTS AND DISCUSSION}

Diffuse reflectance infrared spectroscopy is a sensitive tool to determine chemical changes of wood material during photodegradation (Tolvaj and Mitsui 2005, Liu et al. 2016, Broda and Popescu 2019, Liu R. et al. 2019, Liu et al. 2019b). The fingerprint area of the IR spectra was investigated in this study because the most important changes happened here. The fingerprint area for wood is highly overlapped by the absorption bands of the individual chemical groups. Difference spectrum method was applied because in this case only the changes are visible. Fig. 1 presents the effects of the first UV treatment and water leaching. The black solid line shows chemical changes after 1-day UV treatment. It displays the degradation of guaiacyl lignin absorbing at $1507 \mathrm{~cm}^{-1}$. This negative peak is visible together with the absorption decrease of the aromatic $\mathrm{C}-\mathrm{H}$ deformation at 1469 and $1428 \mathrm{~cm}^{-1}$ and with the absorption decrease of the guaiacyl ring breathing at $1267 \mathrm{~cm}^{-1}$. The absorption decrease of syringyl lignin is visible as a negative peak at $1594 \mathrm{~cm}^{-1}$. As a consequence of lignin degradation, the unconjugated carbonyl band increased between 1670 and $1820 \mathrm{~cm}^{-1}$. This absorption increase consists of a peak at $1759 \mathrm{~cm}^{-1}$ and a broad shoulder around $1723 \mathrm{~cm}^{-1}$ wavenumber. Further treatments resulted in a difference in intensity ratio of this two bands. The intensity increase of the shoulder was greater than the intensity increase of the peak at $1759 \mathrm{~cm}^{-1}$ (see further figures). These two bands represent the absorption of $\mathrm{CO}$ stretching for unconjugated ketones and aliphatic carboxyl groups. 
Absorption decrease is visible at 1173 and $1136 \mathrm{~cm}^{-1}$. The first decrease belongs to the asymmetric stretching of ether bond while the second belongs to the symmetric stretching of ether bond, the aromatic $\mathrm{C}-\mathrm{H}$ deformation and to the glucose ring vibration. These absorption decreases indicate the ether splitting and the degradation of cellulose (Tolvaj and Faix 1995). The subsequent one-day water leaching did not affect the lignin but reduced the UV radiation generated absorption peak at $1759 \mathrm{~cm}^{-1}$. The shoulder at $1723 \mathrm{~cm}^{-1}$ wavenumber, however, remained mainly intact. The next two days of UV radiation (grey line) reduced the guaiacyl lignin content absorbing at $1507 \mathrm{~cm}^{-1}$. As the result of the lignin degradation, the absorption increased considerably in the (1670 and $\left.1820 \mathrm{~cm}^{-1}\right)$ unconjugated carbonyl region.

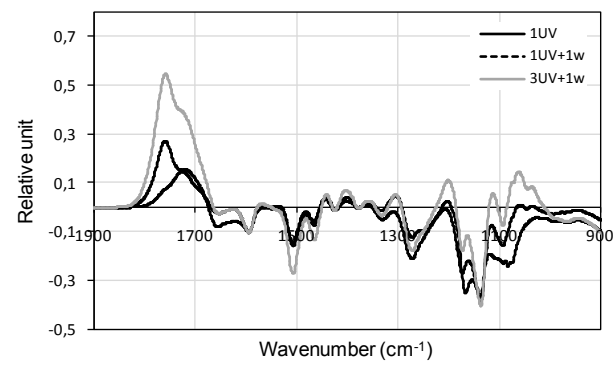

Fig. 1: Difference IR spectra of poplar generated by $U V$ radiation and water leaching. Legend: $1 U V=1$-day $U V$ treatment, $x U V+y w$ where $x$ is the duration of $U V$ treatment and $y$ is the duration of water leaching treatment in days.

No significant difference was found between the effects of the 3-day pure UV treatment and the $3 U V+1 w$ combined UV radiation and leaching treatment (Fig. 2). The second day of water leaching $(3 \mathrm{UV}+2 \mathrm{w})$ removed most part of the UV generated carbonyl groups and the distance between the two peaks increased. The band at $1762 \mathrm{~cm}^{-1}$ was more sensitive to the leaching than the band at $1715 \mathrm{~cm}^{-1}$. The next two days of UV irradiation $(5 \mathrm{UV}+2 \mathrm{w})$ continued the degradation of lignin but the absorption increase in the unconjugated carbonyl region proved to be smaller than during the 3-day pure UV treatment. This is because water leaching removed some part of the unconjugated carbonyls.

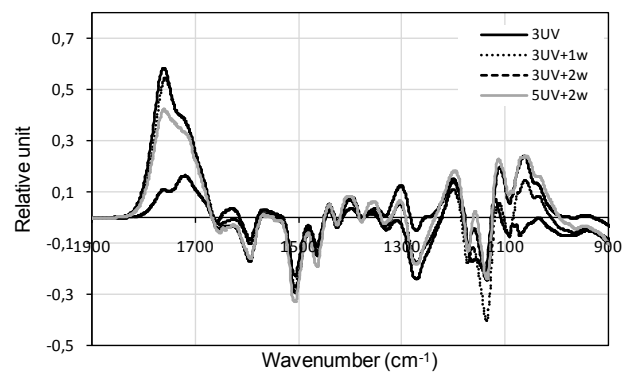

Fig. 2: Difference IR spectra of poplar generated by UV radiation and water leaching. Legend: $3 U V=3-$ day $U V$ treatment, $x U V+y w$ where $x$ is the duration of $U V$ treatment and $y$ is the duration of water leaching treatment in days.

A lifting effect is visible in the $1000-1200 \mathrm{~cm}^{-1}$ wavenumber interval in Fig. 2 if we compare Fig. 1 and Fig. 2. (This effect is even more pronounced on Figs. 3-4.) However, this cannot be real 
absorption increase in a broad wavenumber interval. This is because the Kubelka-Munk (K-M) equation does not provide the absorption spectrum properly if the surface roughness changes and the absorption is high enough. The K-M equation calculates the quotient of the absorption coefficient and the scattering coefficient. The shape of $\mathrm{K}-\mathrm{M}$ function gives the absorption function properly if the light scattering remains constant during a treatment. But the photodegradation and the water leaching increases the surface roughness (Tolvaj et al. 2014). The swelling lifts up the fibre edges during water leaching, and these fibres never return to the original position during drying. This phenomenon is also responsible for the change of surface roughness. Detailed discussion of this lifting phenomenon can be found in a previous work (Tolvaj et al. 2011). The history of the negative peak at $1092 \mathrm{~cm}^{-1}$ in Figs. 1-4 shows properly the lifting effect. The well visible negative peak at $1092 \mathrm{~cm}^{-1}$ in Fig. 1 is already a positive valley between two positive bands in Figs. 2-4. The large K-M value increase overlaps the real absorption changes, interfering the evaluation of the K-M spectrum in the $1000-1200 \mathrm{~cm}^{-1}$ wavenumber interval.

Further cycles of UV irradiation and water leaching generated similar but more intensive changes as the first two cycles. The absorption in the unconjugated carbonyl region (1670 and $1820 \mathrm{~cm}^{-1}$ ) showed large differences between the effects of pure UV treatment and that of combined treatments (Fig. 3).

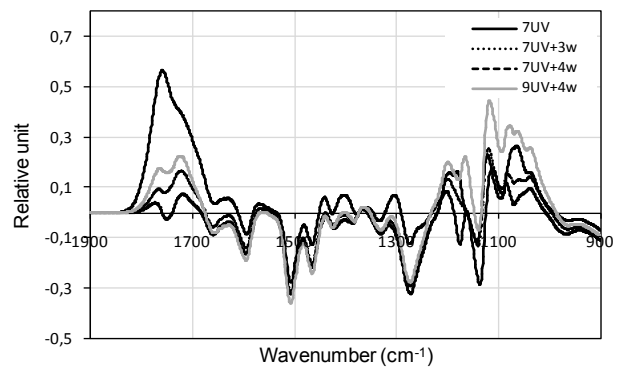

Fig. 3: Difference IR spectra of poplar generated by $U V$ radiation and water leaching. Legend: $7 U V=7$-day $U V$ treatment, $x U V+y w$ where $x$ is the duration of $U V$ treatment and $y$ is the duration of water leaching treatment in days.

The leaching effect is well visible. Leached samples showed much lower absorption in this region than non-leached ones. The intensity order of the two bands has also changed. The band at $1715 \mathrm{~cm}^{-1}$ showed greater stability against water leaching than the band at 1763 $\mathrm{cm}^{-1}$. The fourth day of leaching $(7 \mathrm{UV}+4 \mathrm{w})$ produced a small negative peak at $1745 \mathrm{~cm}^{-1}$ wavenumber. (This phenomenon is much more visible in Fig. 4.) This absorption decrease reduced the intensity of the band at $1763 \mathrm{~cm}^{-1}$ and pushed the maximum towards higher wavenumbers. The reason of the negative peak is that the water leached out carbonyl groups that used to be in the wood. Similar results were found in earlier works (Csanady et al. 2015, Bejo et al. 2019). The interpretation of the changes in the $1000-1200 \mathrm{~cm}^{-1}$ wavenumber interval is questionable because of the lifting effect. However, one absorption increase is remarkable at $1114 \mathrm{~cm}^{-1}$. This peak grown up faster than the lifting effect produced increase (see Fig. 4 as well). This band is attributed to glucose ring stretching vibration in cellulose and to aromatic $\mathrm{C}-\mathrm{H}$ vibration in lignin. This effect may be due to the percentage increase of crystalline cellulose due to the cleavage and dehydration of amorphous carbohydrates and/or crystallization of the paracrystalline region of cellulose (Forschuber et al. 2013). 


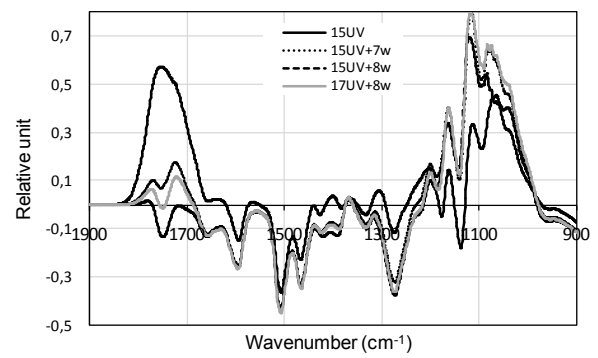

Fig. 4: Difference IR spectra of poplar generated by $U V$ radiation and water leaching. Legend: $15 U V=15$-day $U V$ treatment, $x U V+y w$ where $x$ is the duration of $U V$ treatment and $y$ is the duration of water leaching treatment in days.

The absorption decreases generated by both guaiacyl and syringyl lignin degradation intensified during the whole investigated treatment period. Leached samples suffered greater lignin degradation compared to purely UV irradiated samples (Fig. 4). The band at $1763 \mathrm{~cm}^{-1}$ stopped growing after the seventh day of pure UV irradiation, while the gain of the band at $1715 \mathrm{~cm}^{-1}$ was continuous.

It is well visible that 8 days of leaching treatment generated enormous absorption decrease at $1745 \mathrm{~cm}^{-1}$. This negative peak overlaps the neighbour positive peaks at 1715 and $1763 \mathrm{~cm}^{-1}$. This overlap reduces the intensity of both positive peaks and push the maxima away from each other. The overlapping and the leaching effect eliminated the whole absorption increase in the whole $1670-1820 \mathrm{~cm}^{-1}$ wavenumber interval.

Fig. 5 presents the peak position of the absorption increase originally located at $1759 \mathrm{~cm}^{-1}$. This peak position slightly moved towards higher wavenumbers up to the fifth day of pure UV irradiation. After this period, the position of the peak moved towards lower wavenumbers. After 13 days of pure UV treatment the movement became intensive. The reason of the continuous movement was the neighbour absorption increase at $1715 \mathrm{~cm}^{-1}$. The band intensity at $1715 \mathrm{~cm}^{-1}$ increased faster than the intensity of the band at $1759 \mathrm{~cm}^{-1} \mathrm{did}$. The superposition of these two neighbouring bands determined the visible peak position. In contrast, the combined treatment (UV+leaching) generated opposite movement of the peak position.

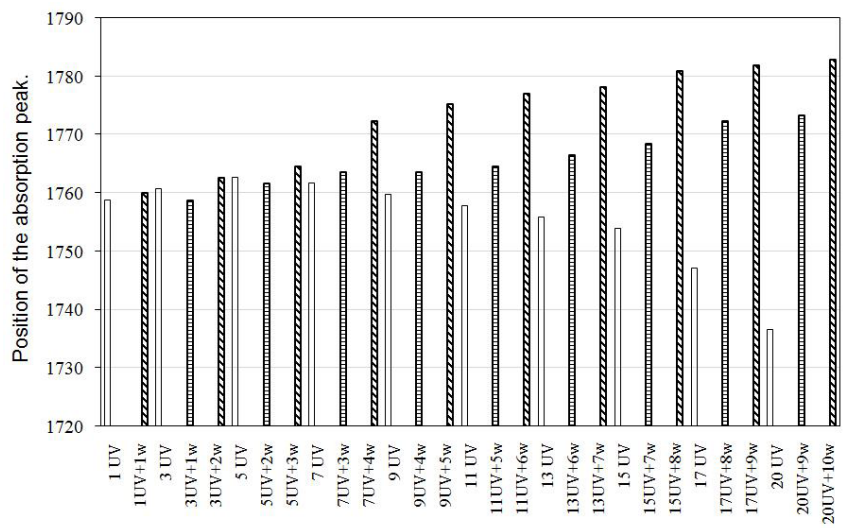

Fig. 5: The wavenumber position of the absorption peak originally located at $1759 \mathrm{~cm}^{-1}$ after different treatments. 
The peak position moved towards higher wavenumbers continuously. This is also the result of a superposition. In this case, a positive (at $1759 \mathrm{~cm}^{-1}$ ) and a negative band (at $1745 \mathrm{~cm}^{-1}$ ) overlapped each other. The UV irradiation elevated intensity of the positive band reducing the previous shift towards higher wavenumbers. But the water leaching generated negative band "snapped" off the lower wavenumber side of the positive band pushing the peak position towards higher wavenumbers.

Fig. 6 shows the change of the absorption band intensity of the guaiacyl lignin at $1507 \mathrm{~cm}^{-1}$. The intensity of the absorption band for guaiacyl lignin decreased continuously during the whole treatment period presenting the lignin degradation. The pure UV irradiation generated negligible absorption degrease after 11 days treatment. Leached samples suffered considerably greater lignin degradation than the samples getting only UV radiation after five days of UV treatment. Similar results were found in a previous work (Bejo et al. 2019). The reason might be that water leaching gives further access for the UV radiation to degrade aromatic rings of lignin in deeper layers of the samples.

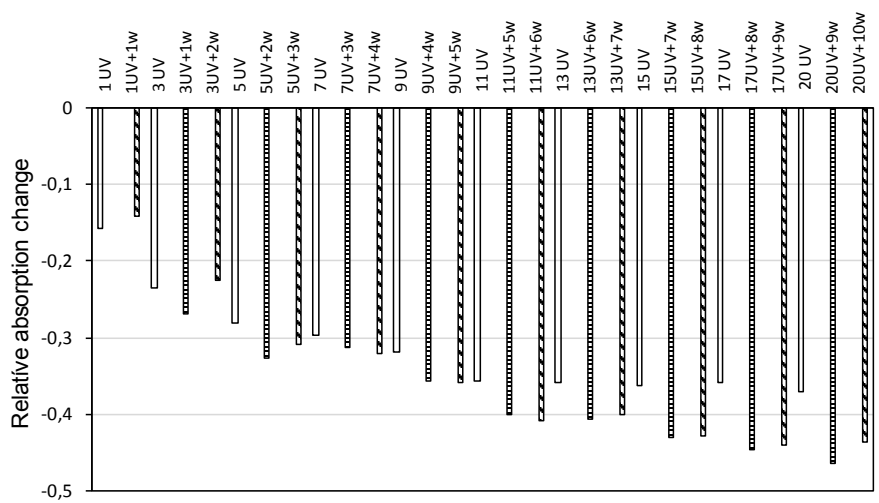

Fig. 6: The change of the absorption band intensity of the guaiacyl lignin at $1507 \mathrm{~cm}^{-1}$.

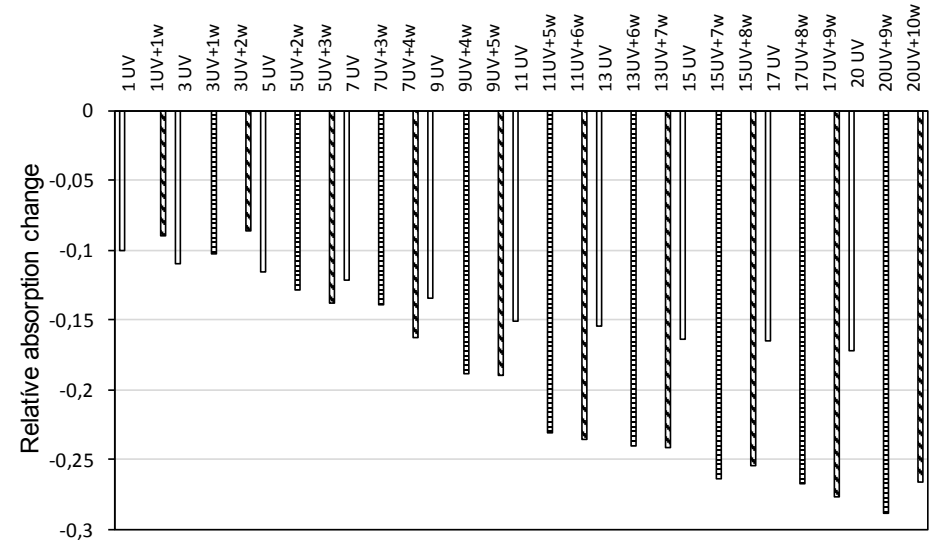

Fig. 7: The change of the absorption band intensity of the syringyl lignin at $1594 \mathrm{~cm}^{-1}$. 
The absorption change of syringyl lignin at $1594 \mathrm{~cm}^{-1}$ was similar to the absorption change of guaiacyl lignin, only the intensity values were smaller (Fig. 7). The degradation of syringyl lignin continued throughout the whole investigated treatment period. Water leached samples suffered considerably greater lignin degradation than the samples suffering only UV radiation, after five days of UV treatment. One reason might be that the leaching by water gives further access for the UV radiation to degrade the aromatic rings of lignin in deeper layers of the samples. The other reason can be that water removed conjugated carbonyl groups. The conjugated carbonyls in lignin and in extractives, and quinone carbonyl groups absorb between $1590-1690 \mathrm{~cm}^{-1}$. In a previous work, colour measurement showed that the leaching partly removed both yellow and red chromophore molecules (Kannar et al. 2018). Figs. 3-4 also demonstrate a negative shift in the $1590-1690 \mathrm{~cm}^{-1}$ wavenumber interval. The negative shift might be generated by the leached conjugated carbonyl groups. The superposition of the absorption decrease of the syringyl lignin and the absorption decrease of the conjugated carbonyls could be the second reason leading to considerable absorption decrease in the case of leached samples (Fig. 7).

\section{CONCLUSIONS}

Poplar samples were irradiated using ultraviolet light emitter mercury lamp. Other series of specimens were treated with the combination of UV radiation and water leaching. Chemical changes were monitored by DRIFT IR spectroscopy. IR measurement was carried out both after UV radiation and water leaching to track both effects separately.

Greater lignin degradation was found in leached samples than in purely UV treated samples. The guaiacyl and the syringyl lignin shoved similar degradation properties. The unconjugated carbonyl groups generated by the photodegradation were the most sensitive chemical components to leaching. As a consequence of photodegradation two absorption bands of unconjugated carbonyl groups were grown up at 1715 and $1759 \mathrm{~cm}^{-1}$ wavenumbers. The band at $1759 \mathrm{~cm}^{-1}$ was much more sensitive to leaching by water than the band at $1715 \mathrm{~cm}^{-1}$. Ten days of water leaching was long enough to remove all unconjugated carbonyls generated by the photodegradation. The water was able to leach out carbonyl groups (absorbing at $1745 \mathrm{~cm}^{-1}$ ) originally presented in poplar wood as well.

\section{ACKNOWLEDGEMENT}

This research was sponsored by the OTKA K116216 "Complex analysis of the physicomechanical and surface-physical properties of wood with low density" project. The financial support is gratefully acknowledged.

\section{REFERENCES}

1. Bejo, L., Tolvaj, L., Kannar, A., Preklet, E., 2019: Effect of water leaching on photodegraded spruce wood monitored by IR spectroscopy. Journal of Photochemistry and Photobiology A: Chemistry 382: Paper: 111948.

2. Broda, M., Popescu, C.M., 2019: Natural decay of archaeological oak wood versus artificial degradation processes - An FT-IR spectroscopy and X-ray diffraction study. Spectrochimica Acta. Part A-Molecular and Biomolecular Spectroscopy 209: 280-287. 
3. Calienno, L., Pelosi, C., Picchio, R., Agresti, G., Santamaria, U., Balletti, F., Lo Monaco, A., 2015: Light-induced color changes and chemical modification of treated and untreated chestnut wood surface. Studies in Conservation 60: 131-139.

4. Chang, T.C., Chang, H.T., Wu, C.L., Chang, S.T., 2010: Influences of extractives on the photodegradation of wood. Polymer Degradation and Stability 95: 516-521.

5. Cogulet, A., Blanchet, P., Landry, V., 2016: Wood degradation under UV irradiation: A lignin characterization. Journal of Photochemistry and Photobiology B: Biology 158: 184-191.

6. Csanady, E., Magoss, E., Tolvaj, L., 2015: Quality of machined wood surfaces. Springer Verlag, Pp 41-91.

7. Fan, Y., Gao, J., Chen, Y., 2010: Colour responses of black locust (Robinia pseudoacacia L.) to solvent extraction and heat treatment. Wood Science and Technology 44: 667-678.

8. Forsthuber, B., Müller, U., Teischinger, A., Grüll, G., 2013: Chemical and mechanical changes during potooxidation of an acrylic clear wood coat and its prevention using UV absorber and micronized $\mathrm{TiO}_{2}$. Polymer Degradation and Stability 98: 1329-1338.

9. Fufa, S.M., Jelle, B.P., Hovde, P.J., 2013: Weathering performance of spruce coated with water based acrylicpaint modified with $\mathrm{TiO} 2$ and clay nanoparticles. Progress in Organic Coatings 76: 1543-1548.

10. Hansmann, C., Deka, M., Wimmer, R., Gindl, W., 2006: Artificial weathering of wood surfaces modified by melamine formaldehyde resin. Holz als Roh und Werkstoff 64(3): 198-203.

11. Kamdem, P., Greiler, S., 2002: Surface roughness and color change of cooper amine and UV absorber-treated red maple (Acer rubrum) exposed to artificial ultraviolet light. Holzforschung 56(5): 473-478.

12. Kannar, A., Tolvaj, L., Magoss, E., 2018: Colour change of photodegraded spruce wood by water leaching. Wood Research 63: 935-946.

13. Liu, X.Y., Timar, M.C., Varodi, A.M., Yi, S.L., 2016: Effects of ageing on the color and surface chemistry of Paulownia wood ( $P$. elongata) from fast growing crops. BioResources 11(4): 9400-9420.

14. Liu, R., Zhu, H., Li, K., Yang, Z., 2019: Comparison on the aging of woods exposed to natural sunlight and artificial xenon light. Polymers 11(4) Paper: 709.

15. Liu, X.Y., Liu, M., Lv, M.Q., Lv, J.F., 2019/a: Photodegradation of three hardwood species by sunlight and xenon light source. BioResources 14(3): 6969-6922.

16. Liu, X.Y., Timar, M.C., Varodi, A.M., 2019b: A comparative study on the artificial UV and natural ageing of beeswax and Chinese wax and influence of wax finishing on the ageing of Chinese Ash (Fraxinus mandshurica) wood surfaces. Journal of Photochemistry and Photobiology B: Biology 201: Paper: 111607.

17. Miklecic, J., Jirous-Rajkovic, V., Antonovic, A., Spanic, N., 2011: Discolouration of thermally modified wood during simulated indoor sunlight exposure. BioResources 6: 434-446.

18. Oltean, L., Hansmann, C., Nemeth, R., Teischinger, A., 2010: Wood surface discolouration of three Hungarian hardwood species due to simulated indoor sunlight exposure. Wood Research 55: 49-58.

19. Pandey, K.K., 2005: Study of the effect of photo-irradiation on the surface chemistry of wood. Polymer Degradation and Stability 90: 9-20.

20. Timar, M.C., Varodi, A.M., Gurau, L., 2016: Comparative study of photodegradation of six wood species after short-time UV exposure. Wood Science and Technology 50: 135-163. 
21. Persze, L., Tolvaj, L., 2012: Photodegradation of wood at elevated temperature: Colour change. Journal of Photochemistry and Photobiology B: Biology (108): 44-47.

22. Preklet, E., Tolvaj, L., Bejo, L., Varga, D., 2018: Temperature dependence of wood photodegradation. Part 2: Evaluation by Arrhenius law. Journal of Photochemistry and Photobiology A: Chemistry 356: 329-333.

23. Sharratt, V., Hill, C.A.S., Kint, D.P.R., 2009: A study of early colour change due to simulated accelerated sunlight exposure in Scots pine (Pinus sylvestris). Polymer Degradation and Stability 94: 1589-1594.

24. Teaca, C.A., Rosu, D., Bodirilau, R., Rosu, L., 2013: Structural changes in wood under artificial UV light irradiation determined by FTIR spectroscopy and color measurements. A brief review. BioResources 8: 1478-1507.

25. Tolvaj, L., Faix, O., 1995: Artificial ageing of wood monitored by DRIFT spectroscopy and CIE 1*a*b* color measurements. I. Effect of UV Light. Holzforschung 49: 397-404.

26. Tolvaj, L., Mitsui, K., 2005: Light source dependence of the photodegradation of wood. Journal of Wood Science 51: 468-473.

27. Tolvaj, L., Mitsui, K., 2010: Correlation between hue angle and lightness of light irradiated wood. Polymer Degradation and Stability 95: 638-642.

28. Tolvaj, L., Mitsui, K., Varga, D., 2011: Validity limits of Kubelka-Munk theory for DRIFT spectra of photodegraded solid wood. Wood Science and Technology 45: 135-146.

29. Tolvaj, L., Molnar, Zs., Magoss, E., 2014: Measurement of photodegradation-caused roughness of wood using a new optical method. Journal of Photochemistry and Photobiology B: Biology 134: 23-26.

30. Tolvaj, L., Tsuchikawa, S., Inagaki, T., Varga, D., 2015: Temperature dependence of photodegradation of wood monitored by colour measurement. Wood Science and Technology 49: 1225-1237.

31. Varga, D., Tolva,j L., Tsuchikawa, S., Bejo, L., Preklet E., 2017: Temperature dependence of wood photodegradation monitored by infrared spectroscopy. Journal of Photochemistry and Photobiology A: Chemistry 348: 219-225.

\author{
Zoltan Pasztory \\ University OF SOPRon \\ InNOVATION CENTER \\ Bajcsy Zs. U. 4 \\ Hu-9400 Sopron \\ Hungary \\ Laszlo Tolvaj", Denes Varga \\ University of Sopron \\ Institute of Physics and Electrotechnics \\ Bajcsy Zs. U. 4 \\ Hu-9400 Sopron \\ Hungary \\ *Corresponding author: tolvaj.laszlo@uni-sopron.hu
}

